\title{
EVALUATION OF SILVER AND COPPER OXIDE NANOPARTICLES RELEASE FROM DIFFERENT PROSTHETIC MATERIALS INCORPORATED WITH NANOPARTICLES
}

\author{
Ahmed M Shoeib *, Maie M Shaker ${ }^{* *}$, Reem M Abdeen ${ }^{* *}$ and Azza A El-Segai***
}

\begin{abstract}
The purpose of this study was to evaluate the amount of released of silver and copper oxide nanoparticles when they were incorporated in heat cured acrylic resin denture, chemical cured soft liner, and cream type adhesive.

Material and methods: A total number of 240 samples were prepared, 80 denture base samples, 80 liner, and 80 adhesives, and 10 samples from each material were free from nanoparticles that act as a control. The remaining samples were divided into two groups: (Group I) contained denture base, liner and adhesive samples modified with copper-oxide nanoparticles concentration by $(0.1 \%$, $0.3 \%$, and $0.5 \%, 10$ sample each), and (Group II) has the same number of samples but modified with same silver nanoparticles concentrations. The samples were placed in distilled water for one week and the amount of release was measured by spectrophotometer. The recordings data were analyzed using Two-way repeated measures Analysis of Variance (ANOVA) to compare between the three groups as well as to study the effect of time within each group. Bonferroni's post-hoc test was used for pair-wise comparisons. $\mathrm{P}<0.05$ was considered.
\end{abstract}

Results: Release was higher in denture adhesive followed by denture liner and denture base respectively in the two groups. The amount of release increased with increasing nanoparticles concentration in denture base and adhesive but not in denture liner. There was no significant difference between Group I, and Group II.

Conclusion: Nanoparticle release was affected by the type of prosthetic material, nanoparticle concentration, but not nanoparticles type.

KEY WORDS: Nanodentistry, silver nanoparticles, copper oxide nanoparticles, denture base, denture liner, denture adhesive.

\footnotetext{
* Lecturer of Removable Prosthodontics, Faculty of Dentistry, Al-Azhar University.

** Lecturer of Removable Prosthodontics, Faculty of Dentistry, Misr International University

*** Assistant Professor of Prosthodontics, Faculty of Dentistry, Tanta University.
} 


\section{INTRODUCTION}

Polymethymethacrylate (PMMA) is a standout amongst the most generally utilized material in prosthetic dentistry. Since its presentation into dentistry it has been effectively utilized for denture bases because of the simplicity of its preparing, ease, shading coordinating capacity, and light weight. It is additionally utilized for some appliances, for example, splints, stents, and night guards ${ }^{(1)}$ The utilization of soft liners delivered a psychological improvement in masticatory capacity, comfort and fulfillment compared with hard denture liners. Besides, the viscous behavior of the soft lining materials was observed to be a significant factor of this improvement, while in hard processed and cold cured, loss of cushioning continues over time (2) more noteworthy improvement in masticatory function ${ }^{(3)}$. Denture adhesives are utilized to build the maintenance of trial denture bases during jaw relation, try in, with denture base during addition of dentures, and with dry mouth patients ${ }^{(4)}$.

Nanotechnology has numerous modern applications in industry including electronic, human services, synthetic, beauty care products, composites and energy fields ${ }^{(5)}$. In dentistry nanoparticles has a developing use as in local anesthesia, cancer diagnosis and treatment, mouthwash or toothpaste containing nanoparticles, impression material, composite fillings, implants, and bone replacement ${ }^{(6)}$. Kamikawa et al ${ }^{(7)}$ demonstrated that the coated heat cured acrylic resin with silver nanoparticles reduce Candida albicans adhesion after 1, 3, 5, and 24 hours at $37^{\circ} \mathrm{C}$. The longer incubation time, less adhesion will be. $\mathrm{Rad}$ et al ${ }^{(8)}$ compared the compressive strength, tensile strength and thermal conductivity of acrylic base of complete dentures with those of acrylic reinforced with silver nanoparticles. They proposed that the mean thermal conductivity and compressive quality silver nanoparticles in denture base material were altogether higher than the unmodified acrylic.
Copper oxide has shown a great activity against Candida albicans ${ }^{(9)}$. Ramazanzadeh et al (10) demonstrated that incorporation of copper oxide nanoparticles in orthodontic brackets significantly reduce the amount of S. Mutans biofilm. Ginjupalli et al (11) found that alginates consolidated with copper oxide nanoparticles displayed antimicrobial action without and adverse effect on strength, gelation time, flow of impression and permanent deformation.

In fact, both engineered and incidentally, released nanoparticles may share a few common adverse effects on human health wellbeing. The level of poisonous degree is dependent on the shape, size, and grouping of the discharged nanoparticles ${ }^{(12)}$. So, it is useful to quantify the measure of the amount of released nanoparticles when incorporated from the different prosthetic materials in order to understand their toxicity.

\section{MATERIALS AND METHODS}

A total number of two hundred and ten specimens were prepared. Thirty samples of heat cured acrylic resin denture base (Acrostone, Egypt), chemical cured acrylic resin denture liner (Acrostone, Egypt), and cream type denture adhesive (Corega, Galaxo Smithkline, England) were free from nanoparticles and used as a control (ten samples each). The remaining samples were divided into two groups: (Group I) contained Copper- oxide nanoparticles, and (Group II) contained silver nanoparticles. Each group had thirty samples of denture base containing $(0.1 \%, 0.3 \%$, and $0.5 \%)$ of either silver or copperoxide nanoparticles (ten samples each). The same was done for denture liner and adhesive.

Silver and copper oxide nanoparticles solution (spherical shape, $<10 \mathrm{~nm}$ ) were measured and added to the monomer of both denture base and denture liner. The powder of acrylic resin was mixed with nanoparticles containing liquid according to manufacturer instructions. The material was 
mixed until dough stage and packed in $2 \mathrm{~cm}$ X $2 \mathrm{~cm}$ metallic mold. For heat cured acrylic resin denture base, the mold was packed and set in hot water bath according to manufacturer instructions. For chemical cured denture liner, the mold was left until curing. In denture adhesive samples, nanoparticles were added directly in the adhesive and then spreaded over heat cured samples $(2 \mathrm{~cm}$ X $2 \mathrm{~cm})$ free from nanoparticles. Each sample was placed in $10 \mathrm{ml}$ distilled water for one week then the amount of the released silver and copper nanoparticle ions were measured by spectrophotometer.

\section{Statistical Analysis}

Numerical data were explored for normality by checking the distribution of data and using Shapiro-Wilk test of normality. Data showed normal (parametric) distribution. Data were presented as mean and standard deviation (SD) values. Two-way repeated measures Analysis of Variance (ANOVA) was used to compare the amount of release between the two groups as well as to study the effect of time, concentration, and material. Bonferroni's posthoc test was used for pair-wise comparisons. The significance level was set at $\mathrm{P} \leq 0.05$. Statistical analysis was performed with IBM SPSS ${ }^{\complement}$ Statistics Version 20 for Windows.

\section{RESULTS}

The mean values of release in $\mathrm{ug} / \mathrm{ml}$ are represented in table (1) and figure (1). Data showed increased release by increasing concentration in both denture base and adhesive within each group. On the other hand, the release in the denture liner of both groups was the greatest in $0.1 \%$ concentration followed by $0.3 \%$ and $0.5 \%$ respectively. The amount of release was higher in denture adhesive than denture liner followed by denture base. The amount of release between both groups showed closer values.

Table (2) showed statistically significant difference between various concentration and

TABLE (1) The mean values of nanoparticles release in both groups (ug/ml)

\begin{tabular}{|c|c|c|c|}
\hline \multirow[b]{2}{*}{ Type } & \multirow[b]{2}{*}{ Concentration } & \multicolumn{2}{|c|}{ Material } \\
\hline & & $\begin{array}{c}\text { Copper-oxide Nanoparticles } \\
\text { (Group I) }\end{array}$ & $\begin{array}{c}\text { Silver nanoparticles } \\
\text { (Group II) }\end{array}$ \\
\hline \multirow{4}{*}{ Denture base } & Control & \multicolumn{2}{|c|}{ Nil } \\
\hline & $0.1 \%$ & $0.001264 \pm 0.000174$ & $0.001327 \pm 0.000182$ \\
\hline & $0.3 \%$ & $0.015163 \pm 0.002086$ & $0.015921 \pm 0.002190$ \\
\hline & $0.5 \%$ & $0.074782 \pm 0.013395$ & $0.078521 \pm 0.014065$ \\
\hline \multirow{4}{*}{ Denture Liner } & Control & \multicolumn{2}{|c|}{ Nil } \\
\hline & $0.1 \%$ & $1.892441 \pm 0.406768$ & $1.987063 \pm 0.427107$ \\
\hline & $0.3 \%$ & $0.605619 \pm 0.129654$ & $0.6359 \pm 0.136137$ \\
\hline & $0.5 \%$ & $0.009613 \pm 0.002058$ & $0.010094 \pm 0.002161$ \\
\hline \multirow{4}{*}{ Denture Adhesive } & Control & \multicolumn{2}{|c|}{ Nil } \\
\hline & $0.1 \%$ & $1.614581 \pm 0.257049$ & $1.69531 \pm 0.269902$ \\
\hline & $0.3 \%$ & $4.085137 \pm 1.204355$ & $4.289394 \pm 1.264572$ \\
\hline & $0.5 \%$ & $8.205128 \pm 1.390872$ & $8.615385 \pm 1.460416$ \\
\hline
\end{tabular}




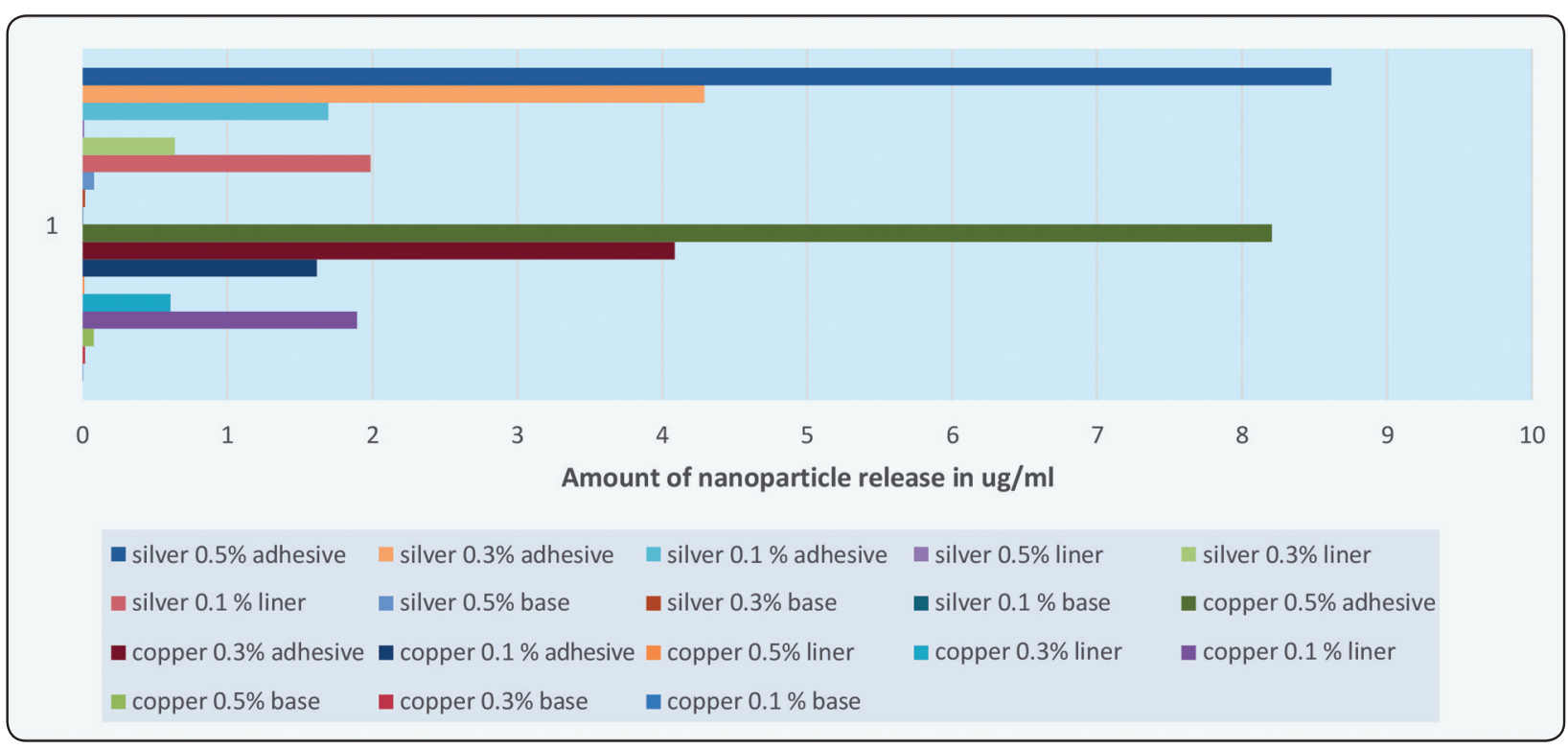

Fig. (1) The mean values of nanoparticles release in both groups (ug/ml)

with the control samples in both groups. Table (3) showed statistically significant difference between denture base, relining material, and adhesive. Table (4) showed that the effect of nanoparticles concentration and different denture types in nanoparticles release was significant. Meanwhile, the different nanoparticles materials have no significant effect on nanoparticles release.

TABLE (2) Comparison between nanoparticles release between different concentrations in both groups $(\mathrm{P}<0.05)$

\begin{tabular}{|c|c|c|c|c|}
\hline \multirow{2}{*}{$\begin{array}{c}\text { (I) } \\
\text { concentration }\end{array}$} & $\begin{array}{c}\text { (J) } \\
\text { concentration }\end{array}$ & $\begin{array}{c}\text { Mean } \\
\text { Difference } \\
(\mathrm{I}-\mathrm{J})\end{array}$ & P value & Significance \\
\hline \multirow{2}{*}{ control } & $0.1 \%$ & $-1.19866414 *$ & .000 & Significant \\
\cline { 2 - 5 } & $0.3 \%$ & $-1.60785584 *$ & .000 & Significant \\
\cline { 2 - 5 } & $0.5 \%$ & $-2.83993088 *$ & .000 & Significant \\
\hline \multirow{2}{*}{$0.1 \%$} & $0.3 \%$ & $-.40919170 *$ & .003 & Significant \\
\cline { 2 - 5 } & $0.5 \%$ & $-1.64126674 *$ & .000 & Significant \\
\hline \multirow{2}{*}{$0.3 \%$} & $0.5 \%$ & $-1.23207504 *$ & .000 & Significant \\
\hline
\end{tabular}

TABLE (3) Comparison between nanoparticles release in different denture types in both groups $(\mathrm{P}<0.05)$

\begin{tabular}{|c|c|c|c|c|}
\hline (I) type & (J) type & $\begin{array}{c}\text { Mean } \\
\text { Difference (I-J) }\end{array}$ & P value & Significance \\
\hline \multirow{2}{*}{ base } & liner & $-.61346110^{*}$ & .000 & Significant \\
\cline { 2 - 5 } & adhesive & $-3.53398671^{*}$ & .000 & Significant \\
\hline liner & adhesive & $-2.92052561^{*}$ & .000 & Significant \\
\hline
\end{tabular}

TABLE (4) Effect of denture type and nanoparticles types and concentration on release of nanoparticles $(\mathrm{P}<0.05)$

\begin{tabular}{|c|c|c|c|c|}
\hline \multicolumn{5}{|c|}{ Dependent Variable: release } \\
\hline Source & $\begin{array}{c}\text { Mean } \\
\text { Square }\end{array}$ & F & P value & Significance \\
\hline Type & 228.212 & 716.934 & .000 & Significant \\
\hline Concentration & 65.866 & 206.919 & .000 & Significant \\
\hline Material & .202 & .636 & .426 & Non-Significant \\
\hline
\end{tabular}




\section{DISCUSSION}

Release of nanoparticles is reliant on polymer nature which enable diffusion of water inside polymer chains. According to the dual-sorption theory, there are two different physical mechanisms that affect mass-transfer: diffusion and embedding (intermolecular forces among penetrant and membrane). The water molecules which initially surrounding the polymeric specimen will broaden the interspace between the polymer chains ${ }^{(13)}$. This lie in agreement with Damm et $\mathrm{al}^{(14)}$, who showed that the release of nanoparticles is higher in hydrophilic solution, which increase the water content inside the polymer. Kang et $\mathrm{al}^{(15)}$ found that the acrylic resin soft denture liners are more hydrophilic and have more surface energy than acrylic resin hard denture liner. Tuna et al found that mass growth by water sorption of heat cured acrylic resin denture base was between $11 \%$ and $30 \%{ }^{(16)}$. In chemical cured acrylic resin denture liner it was $45 \%$ \& $79 \%$ according to Ziral et al ${ }^{(17)}$. Boruvkova et $\mathrm{al}^{(18)}$ showed higher values ofwater sorption of carboxymethyl cellulose in distilled water between $200 \%$ and $1600 \%$. Kumar et $\mathrm{al}^{(19)}$, found that release of silver nanoparticle ions from polyamide polymer is reliant on its absorption.

Higher number of nanoparticles release from denture liner and adhesive more than heat cured acrylic resin denture, and high amount of release with increasing nanoparticle concentration in denture base and adhesive with reverse pattern in denture liner can be clarified by the dual sorption theory, the nature of polymer, and water sorption as stated before. Increasing nanoparticles concentration in the heat cured denture base monomer will increase the amount of the nanoparticles entrapped inside polymer network by the effect of heat during curing leaving few numbers of free nanoparticles outside the polymer. The water diffusion inside the polymer chains is difficult due to the low hydrophilic nature of heat cured denture base polymer. The remaining number of free nanoparticles outside the polymer network become easily flushed with water. Kumar et $\mathrm{al}^{(20)}$ showed that the release of nanoparticles is higher in polymers that have higher degree of crystallinity as denture base. Lim et $\mathrm{al}^{(21)}$ showed that the water sorption is higher in amorphous polymers than polymers with higher crystallinity. The opposite is true for the denture adhesive where water diffusion is easy inside the polymer chains due to high hydrophilicity, which takes more nanoparticles from the polymer chains. On the other hand, in a low concentration of nanoparticles in the denture liner, a greater number of nanoparticles precipitates outside polymer chains. It seems that lack of heat hinders the passage of nanoparticles inside the polymer chains, and more amount of water will absorb inside the liner more than denture base and flush more nanoparticles atoms. With higher concentrations of nanoparticles, more atoms are enforced to trap inside the polymer chains leaving small number of free nanoparticles outside. This is supported by Eurwongpanich et al ${ }^{(22)}$ where Scanning Electron Microscope (SEM) of acrylic soft liners containing silver nanoparticles showed that the nanoparticles are more dispersible on the border of the material more than any other area, it was explained that the silver nanoparticle ions were extruded by polymerize force of materials into border area.

Results of this study is reverse to Monterio et $\mathrm{al}^{(23)}$, where silver Nanoparticle ions were not detected in water from heat cured denture base containing $(0.05 \%, 0.5 \%$, and $5 \%)$ silver nanoparticles (spherical, $60 \mathrm{~nm}$ in diameter). This may be due to the difference in diameter of nanoparticles with our study. Granbohm et $\mathrm{al}^{(24)}$ showed that silver release of nanoparticles from nanocomposite is highly dependent on the size of nanoparticles. Nanoparticles below 20-30 nm in size are characterized by an excess of energy at the surface and are thermodynamically unsteady ${ }^{(25)}$ 
Released values of silver nanoparticles in this study (lower than $10 \mathrm{ug} / \mathrm{ml}$ ) were lower than toxic values silver nanoparticles in vivo studies. Takenaka et al ${ }^{(26)}$ showed liver and neuroendocrine cell lines toxicity at $(10-100 \mathrm{ug} / \mathrm{ml})$ concentrations of silver nanoparticles because of cellular disruption, reduced glutathione (GSH) depletion, reduction of mitochondrial potential, and an increase in reactive oxygen species (ROS). Rosas-Hernández et $\mathrm{al}^{(27)}$ showed toxicity of rat coronary endothelial cells when silver nanoparticles concentration is $(100 \mu \mathrm{g} /$ $\mathrm{ml})$. Samberg et $\mathrm{al}^{(28)}$ showed silver nanoparticles topical skin toxicity of in pigs at $34 \mathrm{ug} / \mathrm{ml}$. The effects were edema, epidermal hyperplasia and focal inflammation. Mahmoud et $\mathrm{al}^{(29)}$ showed highest values of human neuronal cell genotoxicity at copper oxide nanoparticles concentrations 15 $\mathrm{ug} / \mathrm{ml}$, and highest values apoptosis at $40 \mathrm{ug} /$ $\mathrm{ml}$. Ivast et $\mathrm{al}^{(30)}$ showed mice fibroblasts toxicity when copper oxide nanoparticles concentration is $49.9 \mathrm{ug} / \mathrm{ml}$. Transmission electron microscopic analysis study by Wang et $\mathrm{al}^{(31)}$ showed copper oxide nanoparticles toxicity to lung epithelial cells lysosomes, mitochondria, and nucleus occur when copper oxide nanoparticles release is $15 \mathrm{ug} / \mathrm{ml}$.

\section{CONCLUSION}

- Increasing nanoparticles concentration increases nanoparticles release in denture base and adhesive, and vice versa in denture liner in both groups.

- Nanoparticles release was higher in denture adhesive followed by denture liner and denture base respectively in both groups.

- Both silver and copper oxide nanoparticles show insignificant different in release in all denture types.

- All values of release were below the level of the low toxicity of both silver and copper nanoparticles

\section{REFERENCES}

1. Vojdani M, Bagheri R. Effects of aluminum oxide addition on the flexural strength, surface hardness, and roughness of heat-polymerized acrylic resin. J Dent Sci 2012; 7:238-44

2. Mustafa G, Kotane M, Al-Azzawi F. Comparative study of the effects of the denture liners on the mucosa of denture bearing area and on the denture hygiene J Bagh Coll Dentistry 2007;19:50-4.

3. Murata H, Hamada T, Sadamori S. Relationship between viscoelastic properties of soft denture liners and clinical efficacy. Jpn Dent Sci Rev 2007; 44:128-32.

4. Yadav A. Denture Adhesives-their stand in prosthodontics. J Indian Prosthodontic Soc 2005; 5:62-4.

5. Santos C, Gabriel B, Blanchy M, Menes O, García D, Blanco M, Arconada N, et al. Industrial applications of nanoparticles - a prospective overview. Mater Today 2014; $1: 1-11$.

6. Ozak S, Ozkan P. Nanotechnology and dentistry. Eur J Dent 2013; 7:145-51.

7. Kamikawa Y, Hirabayashi D, Nagayama T, Jyunichi Fujisaki, Hamada T, Sakamoto R, Kamikawa Y, et al. In vitro antifungal activity against oralcandidaspecies using a denture base coated with silver nanoparticles. J Nanomater 2014; 1:1-6.

8. Rad F, Ghaffari T, Rezaii F, Ramazani A. Effect of nanosilver on thermal and mechanical properties of acrylic base complete dentures. J Dent (Tehran) 2014; 11:495-505.

9. Karimiyan A, Najafzadeh H, Ghorbanpour M, HekmatiMoghaddam SH. Antifungal Effect of Magnesium Oxide, Zinc Oxide, Silicon Oxide and Copper Oxide Nanoparticles Against Candida albicans. Zahedan J Res Med Sci 2015;17: 2179.

10. Ramazanzadeh B, Jahanbin A, Yaghoubi M, Shahtahmassbi N, Ghazvini K, Shakeri M, Shafaee H. Comparison of Antibacterial Effects of $\mathrm{ZnO}$ and $\mathrm{CuO}$ Nanoparticles Coated Brackets against Streptococcus Mutans. J Dent (Shiraz) 2015; 16:200-5.

11. Ginjupalli K, Alla R, Shaw T, Tellapragada C, Kumar L, Nagaraja P. Comparative evaluation of efficacy of zinc oxide and copper oxide nanoparticles as antimicrobial additives in alginate impression materials. Mater Today: Proceedings 2018; 1:16258-66. 
12. Zoroddu M, Medici S, Ledda A, Nurchi V, Lachowicz J, Peana M. Toxicity of Nanoparticles. Curr Med Chem 2014; $21: 3837-53$.

13. Mi F-L, Wu Y-B, Shyu S-S, Chao A-C, Lai J-Y, Su C-C. Asymmetric chitosan membranes prepared by dry/ wet phase separation: a new type of wound dressing for controlled antibacterial release. J Membr Sci 2003; 212:237-54.

14. Damm C, Münstedt H. Kinetic aspects of the silver ion release from antimicrobial polyamide/silver nanocomposites. Appl Phys A 2008; 91:479- 86.

15. Kang S, Lee H, Hong S, Kim K, Kwon T. Influence of surface characteristics on the adhesion of Candida albicans to various denture lining materials. Acta Odontol Scand 2013; 71:241-48.

16. Tuna SH, Keyf F, Gumus HO, Uzun C. The evaluation of water sorption/solubility on various acrylic resins. Euro J Dent 2008; 2:191-97.

17. Ziral M, Vojdani M, Mohammadi S, Khaledi A-A. Comparison of the Water Sorption and Solubility of Four Reline Acrylic Resins after Immersion in Food-Simulating Agents. J Int Soc Prev Community Dent 2019; 9:40-46.

18. Boruvkova K, Wiener J. Water absorption in carboxymethyl cellulose. Autex Res J 2011; 11:110-3.

19. Kumar R, Münstedt $H$. Silver ion release from antimicrobial polyamide/silver composites. Biomater 2005; 26:2081-88.

20. Kumar R, Münstedt H. Polyamide/silver antimicrobials: effect of crystallinity on the silver ion release. Polymer Inter 2005; 54:1180-86.

21. Lim L, Britt I, Tung M. Sorption and transport of water vapor in nylon 6,6 film. J Appl Polym Sci 1999; 71:197206.

22. Eurwongpanich S, Aimjirakul N, Ekworapoj P. Cytotoxicity of silver nano-prisms containing acrylic denture soft liners. J Dent Assoc Thai 2018; 68:1-10.

23. Monterio D, Gorup F, Takamiya S, de Camargo R, Filho A, Barbosa B. Silver distribution and release from an antimicrobial denture base resin containing silver colloidal nanoparticles. J Prosthdont 2012; 21:7-15.

24. Granbohm H, Larismaa J, Ali S. Control of the size of silver nanoparticles and release of silver in heat treated sio(2)-ag composite powders. Mater (Basel) 2018;11:1-10

25. Auffan M, Rose J, Bottero J, Lowry G, Jolivet J, Wiesner M. Towards a definition of inorganic nanoparticles from an environmental, health and safety perspective. Nature Nanotechnol 2009; 4:634.

26. Takenaka S, Karg E, Roth C, Schulz H, Ziesenis A, Heinzmann U, Schramel P, et al. Pulmonary and systemic distribution of inhaled ultrafine silver particles in rats. Environ Health Perspect 2001; 109:547-51.

27. Rosas-Hernández, Jiménez-Badillo, Martínez-Cuevas, Gracia-Espino, Terrones H, Terrones M, Hussain S, et al. Effects of 45-nm silver nanoparticles on coronary endothelial cells and isolated rat aortic rings. Toxicol Lett 2009; 191:305-13.

28. Samberg M, Oldenburg S, Monteiro N. Evaluation of silver nanoparticle toxicity in skin in vivo and keratinocytes in vitro. Environ Health Perspect 2010; 118:407-13.

29. Abudayyak M, Guzel E, Ozhan G. Copper (II) oxide nanoparticles induce high toxicity in human neuronal cell. Glob J Med Res 2016; 17:262-8.

30. Angela I, Tiina T, Meeri V, Heiki V, Aleksandr K, Mariliis S, Suman P, et al. Toxicity of metal oxide nanoparticles to three mammalian cell types. Curr Top Med Chem 2015; 15:1914-29.

31. Wang Z, Li N, Zhao J, White JC, Qu P, Xing B. CuO nanoparticle interaction with human epithelial cells: cellular uptake, location, export, and genotoxicity. Chem Res Toxicol 2012; 25:1512-21 